\title{
Long-term remission of a Her2/neu positive primary breast cancer under double monoclonal antibody therapy with trastuzumab and bevacizumab
}

\author{
Robert Königsberg',2, Julia Maierhofer ${ }^{1}$, Tanja Steininger ${ }^{1,2}$, Gabriele Kienzer $^{1,3}$, \\ Christian Dittrich ${ }^{1,2}$ \\ ${ }^{1}$ Ludwig Boltzmann Institute for Applied Cancer Research (LBI-ACR VIEnna) - LB Cluster Translational Oncology, $3^{\text {rd }}$ Medical \\ Department - Centre for Oncology and Haematology, Kaiser Franz Josef-Spital, Vienna, Austria \\ ${ }^{2}$ Applied Cancer Research - Institution for Translational Research Vienna (ACR -ITR VIEnna), Vienna, Austria \\ ${ }^{3}$ Institute for Radiodiagnostics, Kaiser Franz Josef-Spital, Vienna, Austria
}

Radiol Oncol 2014; 48(2): 184-188.

Received 27 August 2013

Accepted 18 November 2013

Correspondence to: Robert Königsberg, M.D., ACR-ITR VIEnna, Bernardgasse 24/2, A-1070 Vienna Austria. Phone: +43 6991 4567827; Fax: +43 1 52335944; Email: robert.koenigsberg@gmx.at

Disclosure: No potential conflicts of interest were disclosed.

Background. The attempt to act on several signalling pathways involved in tumour development simultaneously appears to be more attractive than attacking a single target structure alone. Vascular endothelial growth factor (VEGF) over-expression is frequently observed in human epidermal growth factor receptor 2 (Her2/neu) positive patients with breast cancer and over-expression of the proto-oncogene Her2/neu is associated with an up-regulation of VEGF.

Case report. The case of a Her2/neu positive patient with breast cancer who refused cytotoxic chemotherapy with its potential side effects as well as mastectomy is presented. Our patient has been receiving the combined double administration of bevacizumab and trastuzumab for more than 4 years.

Conclusions. This case report shows that (a) the combined double administration of bevacizumab and trastuzumab was be clinically effective. (b) The combination of bevacizumab and trastuzumab is safe and non-toxic. (c) Bevacizumab and trastuzumab can be used as a long-term application.

Key words: breast cancer; Her2/neu; trastuzumab; bevacizumab; VEGF

\section{Introduction}

Vascular endothelial growth factor (VEGF) overexpression is frequently observed in human epidermal growth factor receptor 2 (Her2/neu) positive patients with breast cancer. Over-expression of the proto-oncogene Her2/neu is associated with an upregulation of VEGF. There is, therefore, a biological rationale for targeting both Her2/neu and VEGF pathways in patients with Her2/neu positive breast cancer. We present the case of a postmenopausal patient with Her2/neu positive breast cancer, who received the combined administration of bevacizumab and trastuzumab over a long period of time.
A 58-year-old woman with a newly diagnosed cancer of the right breast was referred to our department for antineoplastic therapy. In order to better understand and justify our further management, the reader has to know that the patient had a history of a psychiatric disorder with long-standing delusional symptoms. She had discontinued antipsychotic drugs because of subjectively perceived worsening. Overall, the patient is socially well integrated. Other known co-morbidities were chronic impairment of renal function after nephrectomy following pyelo-nephritis and diabetes mellitus type II. The first low quality mammography was performed at the outpatient setting, showed two 

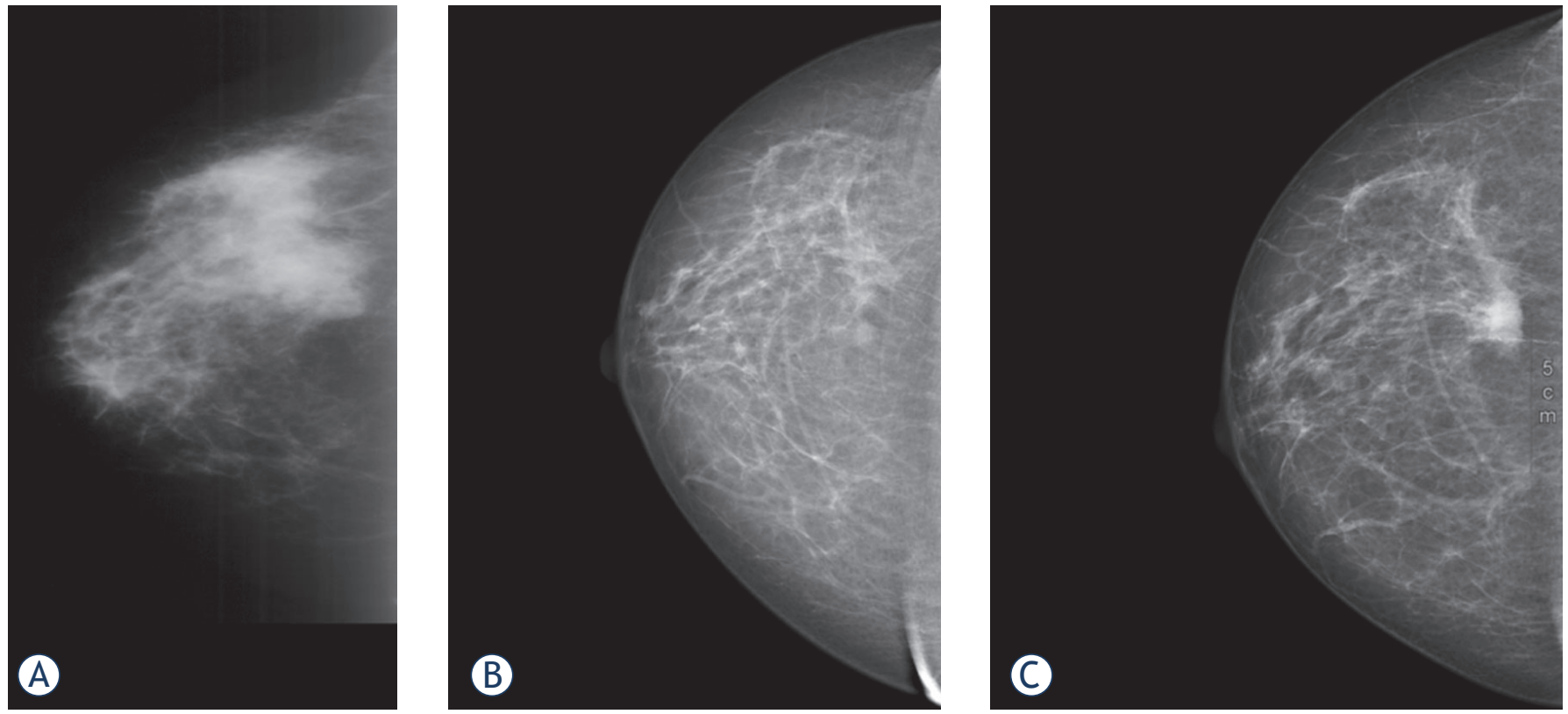

FIGURE 1. A. Low quality mammography showing a polycyclic lesion in the laterocranial quadrant with a diameter of $35 \mathrm{~mm}$ and a second lesion with a diameter of $20 \mathrm{~mm}$ in the centrocaudal quadrant. B. Mammography performed after $25 \mathrm{cycles}$ of trastuzumab and bevacizumab. The former polycyclic lesion in the laterocranial quadrant now has a diameter of $4 \mathrm{~mm}$. The second lesion in the cetntrocaudal quadrant is no more traceable. C. Mammography performed after 74 cycles of trastuzumab and bevacizumab. The lesion in the laterocranial quadrant progressed, measuring $20 \mathrm{~mm}$ in diameter.

masses in the right breast, one lesion with a diameter of $35 \mathrm{~mm}$ and one of $20 \mathrm{~mm}$ (Figure 1A). During the diagnostic evaluation process, the patient refused to repeat the mammography. Biopsy revealed a multi-centric, invasive ductal, grade 2 carcinoma with lymphangiosis. Oestrogen receptor status (ERICA: SI 3, PP 4 (90\%) IRS 12) and Her2/neu receptor status (DAKO lot 30586: 3+) were highly positive, progesterone receptor status was completely negative (PR-ICA: SI 0, PP 0, IRS 0), respectively. Thirty percent of tumor cells had a positive Ki-67 index.

The proposed classical preoperative cytotoxic chemotherapy with its potential side effects as well as mastectomy and axillary lymph node dissection were not reconcilable with the integrity of a female body image, and thus were categorically refused by the patient. Our therapeutic approach therefore focused on the immune-histochemistry data of the Her2/neu positivity and the use of new targeted, non-cytotoxic drugs. As a result, the patient was offered customized, albeit experimental treatment with the humanized monoclonal antibody trastuzumab (Herceptin ${ }^{\circledR}$ ) combined with the humanized monoclonal antibody bevacizumab (Avastin ${ }^{\circledR}$ ).

Therapy was initiated according to Table 1 and repeated on a three weekly base. For the first four cycles of combined antibody therapy the initial bevacizumab dosage of $10 \mathrm{mg} / \mathrm{kg}$ of body weight
(BW) was chosen because the patient refused to accept the internationally recommended dosage of 15 $\mathrm{mg} / \mathrm{kg}$.

After the fourth cycle, a good partial response was documented by mammography. The second lesion with a diameter of $2 \mathrm{~cm}$ was and would be no more traceable throughout the forthcoming mammographies. After 25 cycles of double antibody therapy a further reduction of the tumor mass was observed (Figure 1B). As the patient did not cease refusing surgery categorically, the original treatment was consistently continued. After 8 months of treatment, the bevacizumab dosage was reduced to $7.5 \mathrm{mg} / \mathrm{kg}$ due to the patient's request. After 51 cycles of combined antibody therapy the patient agreed to receive $15 \mathrm{mg} / \mathrm{kg}$ of bevacizumab, according to the recommendation for breast cancer treatment, because mammography presented a suspicious enlargement. The mammography performed after 48 months of therapy, confirmed the persistence of a partial remission compared to the initial outpatient mammography. Four years after diagnosis the patient was free of symptoms related to her malignant disease or the respective treatment which let us maintain therapy unchanged. However, after 74 cycles of combined antineoplastic therapy progression of the lesion was documented by mammography (Figure 1C). 
TABLE 1. Antineoplastic treatment plan of a patient with estrogen - and Her2/neu receptor positive breast cancer

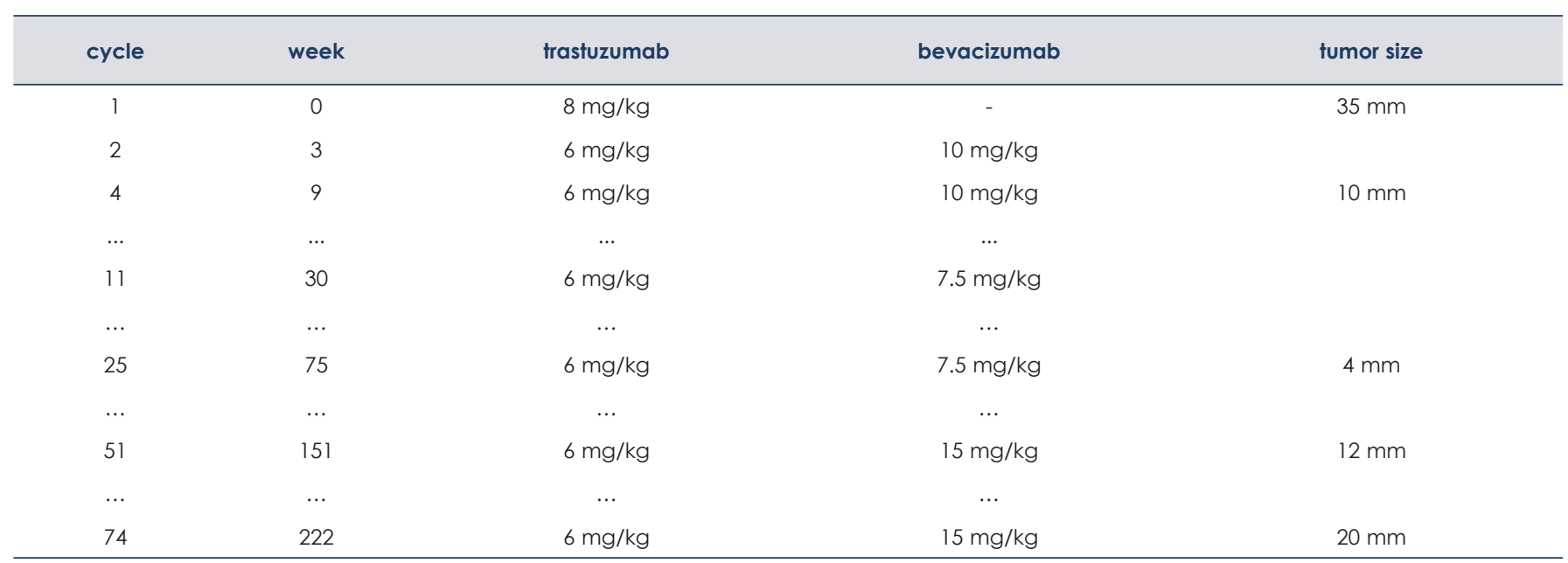

Monitoring of potential cardiac abnormalities, including echocardiography and measuring of NTproBNP levels, have been done repeatedly. Newly diagnosed hypertension was well controlled by ACE inhibitors.

\section{Discussion}

VEGF is a well-established key-factor inducing angiogenesis leading to tumour growth and metastasis. ${ }^{1,2}$ There exists a significant correlation between tumour microvessel density in breast cancer, the presence of axillary lymph node and distant metastases, respectively. ${ }^{3}$ VEGF over-expression is frequently observed in Her2/neu positive patients with breast cancer., ${ }^{4,5}$ Via multiple intracellular pathways VEGF and Her2/neu act at various stages of breast cancer development. ${ }^{6}$ Over-expression of the proto-oncogene Her2/neu is associated with an up-regulation of VEGF in vitro and in vivo. ${ }^{8-9}$ Transfection of Her2/neu over-expression resulted in a rise of VEGF on RNA as well as on protein levels. $^{8-9}$ In vitro VEGF was reduced by exposure to Her2/neu antibodies such as trastuzumab, especially in cells with Her2/neu over-expression. ${ }^{7,9,10}$ Considering VEGF as a possible downstream effector of Her2/neu, which might contribute to the more aggressive phenotype of Her2/neu over-expressing breast cancer cells, Konecny et al., showed a significant association of Her2/neu over-expression and VEGF up-regulation based on tissue samples of 611 unselected breast cancer patients. ${ }^{11}$ In this study, VEGF expression was negatively correlated with survival. These results were concordant with the results of Linderholm et al., thus prompting to a re-evaluation of combined treatment strategies targeting both Her2/neu and VEGF. ${ }^{12}$ On the other hand a paper recently published by Liu et al. showed that in Her2/neu positive breast cancer patients VEGF over-expression was not significantly correlated with breast cancer-specific mortality, distant recurrence or overall mortality, respectively. ${ }^{5}$ These conflicting retrospective results regarding the possible prognostic and predictive value of VEGF over-expression are demanding prospective clinical studies evaluating the benefit of adding bevacizumab to trastuzumab in patients with Her2/neu positive breast cancer.

So far, in a clinical phase I trial, 9 patients were subjected to combination treatment with bevacizumab, 3.0, 5.0 or $10.0 \mathrm{mg} / \mathrm{kg} \mathrm{BW}$, respectively, at intervals of 14 days, and trastuzumab at a loading dose of $4 \mathrm{mg} / \mathrm{kg} \mathrm{BW}$, followed by $2 \mathrm{mg} / \mathrm{kg}$ BW once a week until progression. ${ }^{13}$ Grade 3 and 4 side effects were absent throughout. Grade 1 and 2 side effects consisted of diarrhoea, fatigue and nausea. In addition, one patient developed grade 2 allergic reactions, another one grade 2 hypertension and yet another one grade 2 proteinuria. Left ventricular function did not deteriorate. Bevacizumab combined with trastuzumab was well tolerated. After 6 cycles complete remission was recorded in one, partial remission in 4 , stable disease in 2 and disease progression in 2 patients, respectively. Pharmacokinetic studies showed that the administration of the two drugs on the same day did not alter the pharmacokinetic patterns of either drug. According to this study, the dosage recommended for the phase II trials was $10 \mathrm{mg} / \mathrm{kg}$ BW every 14 
days for bevacizumab and $4 \mathrm{mg} / \mathrm{kg} \mathrm{BW}$ for loading followed by $2 \mathrm{mg} / \mathrm{kg}$ BW once a week for trastuzumab. In this study, one patient had progressed on prior chemotherapy and trastuzumab. Five of 9 patients improved clinically. These data argue in favour of combining anti-Her2/neu and anti-VEGF treatment in patients with Her2/neu-positive breast cancer.

In the very first phase II trial with a combination of these humanized antibodies in breast cancer ${ }^{14}$, the clinical efficacy of combination treatment with trastuzumab and bevacizumab as well as safety and toxicity were evaluated. Patients were initially given trastuzumab at a loading dose of $4 \mathrm{mg} / \mathrm{kg}$ BW and bevacizumab at a dose of $10 \mathrm{mg} / \mathrm{kg} \mathrm{BW}$ on day 7. In the further course, trastuzumab was given at a dose of $2 \mathrm{mg} / \mathrm{kg}$ BW once weekly combined with bevacizumab, $20 \mathrm{mg} / \mathrm{kg} \mathrm{BW}$, at intervals of 2 weeks. Interim analysis of 37 patients treated accordingly showed complete remission in one patient, partial remission in 19 patients, stable disease in 11 and disease progression in 6 patients.

One multicenter phase III trial initiated by the NSABP (BETH Study) will determine the value of adding bevacizumab to chemotherapy plus trastuzumab in patients with resected node-positive or high risk node-negative, Her2/neu-positive breast cance. ${ }^{15}$

To make the regimen more convenient to our patient, we chose a three weekly cycle. This is justifiable nonetheless since bevacizumab displays linear pharmacokinetics, yielding similar exposure with flexible dosage regimens administered on a $\mathrm{mg} / \mathrm{kg}$ basis such as bi- or three-weekly dosing. ${ }^{16}$ Pharmaco-dynamic information collected during clinical trials in phase I to III studies of bevacizumab showed that under treatment with bevacizumab at different dosages, e.g. at a dose of $2.5 \mathrm{mg} /$ $\mathrm{kg}$ per week in colorectal cancer and at $5.0 \mathrm{mg} / \mathrm{kg}$ per week in breast cancer circulating VEGF levels were un-measurable. ${ }^{17,18}$

The initial intention to augment the dosage of bevacizumab to $15 \mathrm{mg} / \mathrm{kg}$ three weekly was finally reached because the patient could be convinced that the internationally recommended dosage of bevacizumab might suspend further tumor growth. Due to our patient's request, she received initially $10 \mathrm{mg} / \mathrm{kg}$ bevacizumab. The dosage was reduced after 11 cycles to $7.5 \mathrm{mg} / \mathrm{kg}$. But even with the lower dosage of bevacizumab further reduction of the tumor mass was observed. This observation might support the effectiveness of lower dosages of bevacizumab which is in line with previously published pharmaco-dynamic studies. On the oth- er hand lowering the dosage of bevacizumab with no detrimental effect on the tumor size might indirectly indicate that the addition of bevacizumab to trastuzumab had little or no benefit which would be in line with some comparable phase III studies in metastatic breast cancer. However, the benefit of trastuzumab in Her2/neu positive breast cancer is indisputable. As a single agent in first-line treatment of Her2/neu positive metastatic breast cancer trastuzumab yielded objective response rate up to $26 \% .^{19}$ Another phase III study (ECOG 1105) currently evaluates this issue studying first-line chemotherapy and trastuzumab to compare how well they work when given with or without bevacizumab in treating patients with metastatic breast cancer that over-expresses Her2/neu. ${ }^{20}$

Currently, the combination of trastuzumab and bevacizumab in the first line treatment of HER2/ neu positive breast cancer is not justified since there are other anti-HER2 drug combinations that have shown more striking results at least in the metastatic setting. ${ }^{21,22}$

\section{Conclusions}

The attempt to act on several signalling pathways involved in tumor development simultaneously appears to be more attractive than attacking a single target structure alone. The combined double administration of bevacizumab and trastuzumab is easily handled, and represents a safe and non-toxic regimen allowing long-term application in patients with Her2/neu-positive recurrent, metastasizing as well as primary breast cancer. Targeting both Her2/ neu and VEGF pathways was effective in our case for a long period of time although we can not say to what extent the benefit is attributed to the addition of bevacizumab and to what extent to trastuzumab solely.

\section{References}

1. Hicklin DJ, Ellis LM. Role of the vascular endothelial growth factor pathway in tumor growth and angiogenesis. J Clin Oncol 2005; 23: 1011-27.

2. Rozman A, Silar M, Kosnik M. Angiogenin and vascular endothelial growth factor expression in lungs of lung cancer patients. Radiol Oncol 2012; 46: 354-9.

3. Weidner N, Semple JP, Welch WR, Folkman J. Tumor angiogenesis and metastasis--correlation in invasive breast carcinoma. N Engl J Med 1991; 324: 1-8.

4. Linderholm B, Bergqvist J, Hellborg $\mathrm{H}$, Johansson $\mathrm{U}$, Linderholm $\mathrm{M}$, von Schoultz E, et al. Shorter survival-times following adjuvant endocrine therapy in oestrogen- and progesterone-receptor positive breast cancer overexpressing HER2 and/or with an increased expression of vascular endothelial growth factor. Med Oncol 2009; 26: 480-90. 
5. Liu Y, Tamimi RM, Collins LC, Schnitt SJ, Gilmore HL, Connolly JL, et al. The association between vascular endothelial growth factor expression in invasive breast cancer and survival varies with intrinsic subtypes and use of adjuvant systemic therapy: results from the Nurses' Health Study. Breast Cancer Res Treat 2011; 129: 175-84.

6. Matos M, Zakotnik B, Grasic Kuhar C. Effectiveness of adjuvant transtuzmab in daily clinical practice. Radiol Oncol 2013; Ahead of print; doi:10.2478/ raon-2013-008. Available from: http://www.degruyter.com/view/j/raon. ahead-of-print/raon-2013-0081/raon-2013-0081.xml?format=INT

7. Petit AM, Rak J, Hung MC, Rockwell P, Goldstein N, Fendly B, et al Neutralizing antibodies against epidermal growth factor and ErbB-2/neu receptor tyrosine kinases down-regulate vascular endothelial growth factor production by tumor cells in vitro and in vivo: angiogenic implications for signal transduction therapy of solid tumors. Am J Pathol 1997; 151: 1523-30.

8. Yen L, You XL, Al Moustafa AE, Batist G, Hynes NE, Mader S, et al. Heregulin selectively upregulates vascular endothelial growth factor secretion in cancer cells and stimulates angiogenesis. Oncogene 2000; 19: 3460-9.

9. Epstein M, Ayala R, Tchekmedyian N, Borgstrom P, Pegram M, Slamon D. HER$2 /$ neu-overexpressing human breast cancer xenografts exhibit increased angiogenic potential mediated by vascular endothelialgrowthfactor(VEGF) [Abstract]. Breast Cancer Res Treat 2002; 76(Suppl 1): S143.

10. Izumi $Y, X u$ L, di Tomaso E, Fukumura D, Jain RK. Tumour biology: herceptin acts as an anti-angiogenic cocktail. Nature 2002; 416: 279-80.

11. Konecny GE, Meng YG, Untch M, Wang HJ, Bauerfeind I, Epstein M, et al. Association between HER-2/neu and vascular endothelial growth factor expression predicts clinical outcome in primary breast cancer patients. Clin Cancer Res 2004; 10: 1706-16.

12. Linderholm B, Andersson J, Lindh $B$, Beckman L, Erlanson $M$, Edin $K$, et al. Overexpression of c-erbB-2 is related to a higherexpression of vascular endothelial growth factor (VEGF) and constitutes anindependent prognostic factor in primary node-positive breast cancer afteradjuvant systemic treatment. Eur J Cancer 2004; 40: 33-42.

13. Pegram M, Yeon C, Ku N, Gaudreault J, Slamon DJ. Phase I combined biological therapy of breast cancer using two humanized monoclonal antibodies directed against HER2 proto-oncogene and vascular endothelial growth factor (VEGF). [Abstract]. Breast Cancer Res Treat 2004; 88(Suppl 1): S124-5.

14. Pegram M, Chan D, Dichmann R, Tar-Chin E, Yeon C, Duran L, et al. Phase II combined biological therapy targeting the HER2 proto-oncogene and the vascular endothelial growth factor using trastuzumab $(T)$ and bevacizumab (B) as first line therapy of HER2 amplified breast cancer. Breast Cancer Res Treat 2006; 100(Suppl 1): S28-9.

15. BETH Study: Treatment of HER2 positive breast cancer with chemotherapy plus trastuzumab vs chemotherapy plus trastuzumab plus bevacizumab. Available at http://clinicaltrials.gov/ct2/show/ NCT00625898?term=BETH\&rank=1

16. Lu JF, Bruno R, Eppler S, Novotny W, Lum B, Gaudreault J. Clinical pharmacokinetics of bevacizumab in patients with solid tumors. Cancer Chemother Pharmacol 2008; 62: 779-86.

17. Kabbinavar F, Hurwitz HI, Fehrenbacher L, Meropol NJ, Novotny WF Lieberman G, et al. Phase II, randomized trial comparing bevacizumab plus fluorouracil (FU)/leucovorin (LV) with FU/LV alone in patients with metastatic colorectal cancer. J Clin Oncol 2003; 21: 60-5.

18. Giantonio BJ, Catalano PJ, Meropol NJ, O'Dwyer PJ, Mitchell EP, Alberts $\mathrm{SR}$, et al. Bevacizumab in combination with oxaliplatin, fluorouracil, and leucovorin (FOLFOX4) for previously treated metastatic colorectal cancer: results from the Eastern Cooperative Oncology Group Study E3200. J Clin Oncol 2007; 25: 1539-44.

19. Gianni L, Romieu GH, Lichinitser M, Serrano SV, Mansutti M, Pivot $X$ et al. AVEREL: a randomized phase III Trial evaluating bevacizumab in combination with docetaxel and trastuzumab as first-line therapy for HER2-positive locally recurrent/metastatic breast cancer. J Clin Oncol. 2013; 10: 1719-25.

20. ECOG 1105: First-line chemotherapy and trastuzumab with or without bevacizumab in treating patients with metastatic breast cancer that overexpresses HER-2/NEU. Available at: http://clinicaltrials.gov/ct2/results?term= ECOG+1105\&Search=Search

21. Baselga J, Cortés J, Kim SB, Im SA, Hegg R, Im YH, et al. CLEOPATRA Study Group. Pertuzumab plus trastuzumab plus docetaxel for metastatic breast cancer. N Engl J Med. 2012; 366: 109-19.

22. Verma S, Miles D, Gianni L, Krop IE, Welslau M, Baselga J, et al. EMILIA Study Group. Trastuzumab emtansine for HER2-positive advanced breast cancer N Engl J Med. 2012; 367: 1783-91. 